\title{
Simulative Investigations of the Influence of Surface Indentations on Residual Stresses on Inner Raceways for Roller Element Bearings
}

\author{
J. Kehl*, R. Drafz, F. Pape, G. Poll \\ Institute for Machine Design and Tribology (IMKT), Leibniz University Hannover \\ Welfengarten 1A, 30167 Hannover, Germany \\ *Tel.: +49(0) 5117622267 E-mail: kehl@imkt.uni-hannover.de
}

\begin{abstract}
Resource-efficient machine elements are in the focus of current research. One of the most widely used machine elements are roller bearings. Thus, the optimization of bearings and their tribological properties promises to result in significant resource savings. Special focus is set on the bearing fatigue life, which may be significantly reduced by indentations on the raceways. The reduction in fatigue life can be caused by processes such as rolling over particles or by brinelling. These processes induce local stress peaks and lead to elastic-plastic deformations of the raceways. During the subsequent operation, the pile up of material around the indentations is flattened and hence the residual stresses change. Inside these so called shoulders stress peaks, residual stresses and hardening effects occur possibly resulting in crack initiation, crack growth under cyclic loading, and eventually spalling of material. For deeper and more sharp-edged indentations the bearing fatigue life is reduced more. To quantify the influence of an indentation on the bearing rating life a calculation model was developed based on the approach of IOANNIDES, BERGLING and GABELLI. For this, a 3DFE model is used to calculate the three dimensional stress fields by superposition of residual and load stresses.
\end{abstract}

\section{Introduction}

When LundGREN and PALMGREN published their life theory in 1947 they focused on the fatigue life of ball bearings which is defined as the time until the first spalling appears [1]. These surface damages are due to cracks that are initiated in the subsurface area and propagate to the surface where they result in the typical fatigue damage. The cracks begin at material defects such as impurities and are initiated foremost by the shear stresses that occur due to the Hertzian pressure in the contact area. Their theory based on the previous works of WEIBULL who introduced the probabilistic approach to engineering [2]. Throughout the 20th century, however, the quality of steels has significantly improved and these material defects could be reduced. Classical subsurface fatigue life became less important [3].

ZARETSKY et. al. conducted a study with approximately 224,000 roller bearings. He estimated the percentage of fatigue failures to only $3 \%$ of all failures whereas particles are held responsible for over $20 \%$ [4]. There are less conservative studies that estimate these failures to over $40 \%$ [5]. GABELLI et al. demonstrated that indentations from hard materials such as corundum can reduce the bearing fatigue life by up to $95 \%$ [6]. To account for such influences on the bearing fatigue life IOANNIDES and HARRIS introduced their advanced theory of bearing life calculation in 1985 [7], [8]. They introduced an analytical approach to consider the cleanliness of the lubricant and indirectly the contamination by particles. Eventually their work was incorporated as easy to handle equations in the ISO 281:2007 [9] and ISO/TS 16281:2008 [10] that set the standards for the advanced bearing life calculation. However, this approach does not explicitly consider the influence of particle contamination. It does not regard the increase in stress caused by the altered geometry of the surface.

To avoid particle damages the present countermeasures solely focus on the cleanliness of the lubricant. Primarily seals and filter systems are used to prevent particles from entering the bearing, but in some cases particles nevertheless enter the contact zone. 
NeUBAUER investigated the fatigue life of roller bearings in which residual stresses were artificially induced by hard turning and deep rolling [11]. These residual stresses were designed to affect the stresses that occur from the Hertzian pressure and cause subsurface fatigue. He observed in this way that the fatigue life of roller element bearings can be increased by the factor of 2.3 . In this study his approach is applied to dented surfaces and to examine the effect on the bearing fatigue life.

\section{FE Model}

Roller bearings of the type NU 206 are investigated in particular in this study. The inner ring of these bearings has the highest risk of failure and hence is in the focus of this study, see Figure 1. The calculation model can be divided into two main steps, see Figure 2. Firstly a FE analysis is conducted that simulates a sphere penetrating a flat surface. This simulation is comparable to a Brinell hardness test, since the said particle is modeled as a rigid undeformable body, because of that the results can be expected to be slightly exaggerated. In earlier simulations a sphere with a radius $150 \mu \mathrm{m}$ was found to achieve the best results. The shape of the flat surface is a cube with an edge length of 300 $\mu \mathrm{m}$. The ball penetrates the surface by $15 \mu \mathrm{m}$ and leaves the surface afterwards at the same amount.

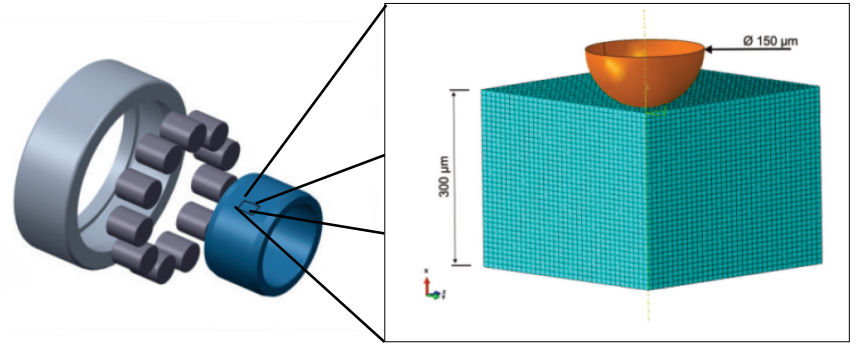

Fig. 1: Initial configuration of model 1

This quasi-static analysis was done twice. Once with residual stresses from the manufacturing process and the second time without. The distribution of the residual stresses is depicted in Figure 3. The commercial CAE software Abaqus 6.11 is used. To save calculation time the axis symmetry was used. Therefore symmetry boundary conditions were used on the y and z symmetry surfaces. On the bottom the model is encastre while on the outer surfaces the degrees of freedom in the $\mathrm{x}$ and $\mathrm{y}$ directions were locked. Standard C3DR elements were used. The model has 35 elements along each edge and thus contains 42875 elements in total. To save more calculation time only the highly loaded volume was investigated in this paper. This is justifiable since the volume elements that will fail and thusly contribute to the fatigue Life are expected to be in the highly loaded volume only.

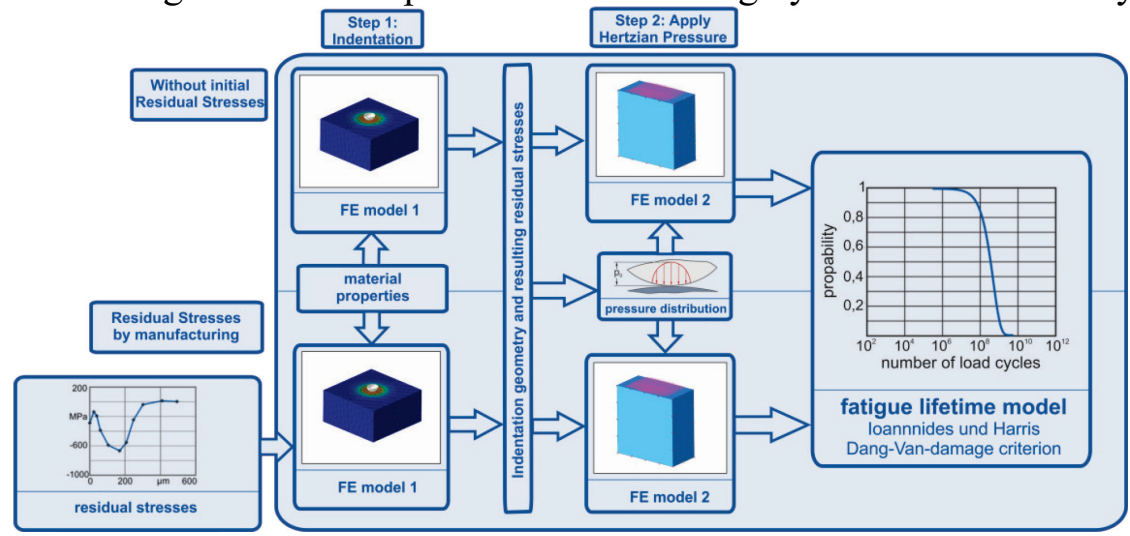

Fig. 2: Calculation scheme of the fatigue life prediction. The calculations are done with and without residual stresses as initial condition. Step 1: the indentation is simulated. Step 2: the resulting residual stresses from step 1 are taken as initial conditions. The indentation diameter and depth are taken to calculate the altered Hertzian contact pressure. The results are evaluated with the bearing fatigue life approach of Ioannides and Harris using the Dang-Van-criterion. 
The material chosen is AISI 52100 (100Cr6) standard bearing steel. The elastic plastic material data were obtained by investigations by HACKE at the TU Clausthal in a common research project, see [12]. The yield strength $R_{p}$ is $1830 \mathrm{~N} / \mathrm{mm}^{2}$ and the tensile strength $R_{m}$ is $2620 \mathrm{~N} / \mathrm{mm}^{2}$. As investigated in [13-17] the hardening behavior of the material influences the development of residual stresses by indentations significantly.

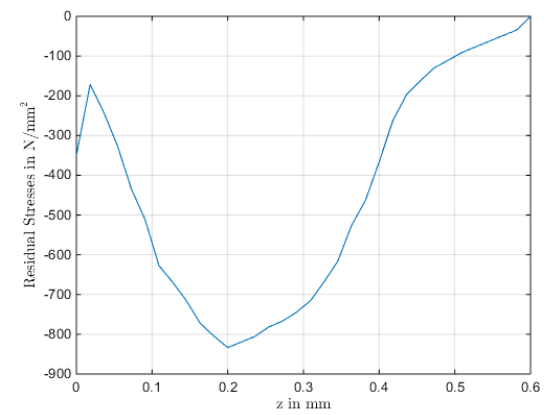

Fig. 3: Residual stress distribution used in the simulation [11].

In the aforementioned papers the authors investigated the plastic deformation depending on different hardening behaviors such as isotropic and kinematic hardening. The results of these studies prove, that the more distinctive the hardening behavior of a material is, the lower the remaining residual stresses and plastic strains are and the smaller the material pile up around an indentation. Therefore a simple isotropic hardening law is established to account for these effects. Contact is standard surface-to-surface-contact with a friction coefficient of 0.2 as described in [14]. From the results of this first step the indentation depth and diameter and the residual stresses that are produced by the particle indentation are obtained to feed the second step.
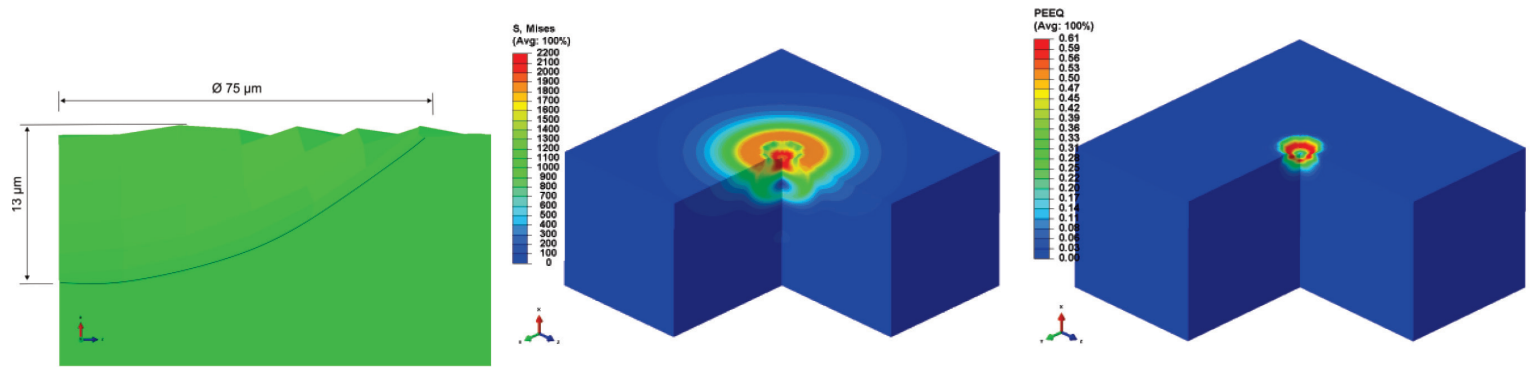

Fig. 4: Results of simulation step 1. The dimensions of the plastically deformed geometry of the surface (left) are used to feed equation one. From that the altered Hertzian contact pressure is calculated. The residual stresses are directly applied to the second model step 2 as initial condition (middle). In the area of contact a significant amount of plastic deformation is observed illustrated by the equivalent plastic strain (left).

The results of step 1 can be seen in Figure 4. Here only the results for the case without residual stresses are depicted. The von Mises stresses show a good agreement with the simulations in the literature mentioned before. There is significant plastic deformation in the contact area of the surface and the ball. The remaining plastic deformation left an indentation of $75 \mu \mathrm{m}$ in diameter with a depth of $13 \mu \mathrm{m}$.

The second step of the calculation consists again of two quasi-static FE analyses. To represent the contact pressure of the roller element a Hertzian contact pressure is applied to the surface of a second model similar to the first one. The Hertzian pressure was adapted to the altered geometry of the surface. To do so, the analytical approach by CoUlon $[18,19]$ was used to avoid complex Elastohydrodynamic calculations of the lubricant film and contact calculations. The altered Hertzian pressure distribution can be seen in Figure 5. The plot shows an increase of the Hertzian pressure by approximately $20 \%$. The governing equation is 


$$
\Delta P=-\frac{\Delta P_{s h}}{\left(\frac{\Phi}{2}\right)^{2}} \cdot\left(\sqrt{X^{2}+Y^{2}}-\Phi\right)^{2}+\Delta P_{s h} \text { with } \Delta P_{s h}=0.7 \frac{\Phi}{D_{t h}}
$$

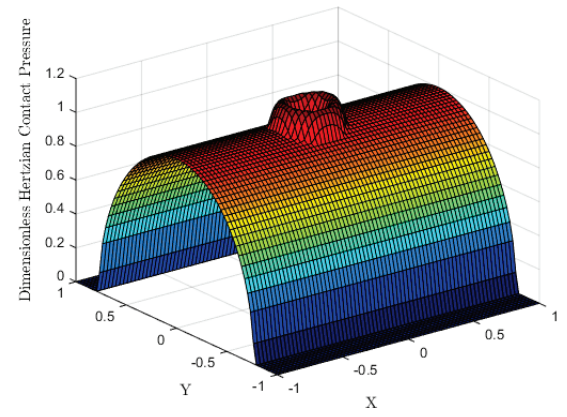

Fig. 5: Dimensionless Hertzian contact pressure at line contact on a dented surface with an indentation diameter of $75 \mu \mathrm{m}$ and a depth of $13 \mu \mathrm{m}$.

With $\Phi$ as the dimensionless indentation diameter and $D_{t h}$ the dimensionless indentation depth.

The peak Hertzian pressure is $2516 \frac{\mathrm{N}}{\mathrm{mm}^{2}}$. The material model is the same as in step one. The residual stresses that remain after the indentation are applied as initial conditions. As the first step has shown, the relevant volume for the second step is much smaller than the actual bearing model. The model for the second step is thus adapted to the size of the first step. The analysis is run both with and without residual stresses.

To evaluate the stresses considering the bearing fatigue life the analytical approach of IOANNIDES and HARRIS for advanced life service is used [8]. Here the classical fatigue life concept of PALMGREN and LUNDBERG is extended by implementing the actual stresses that exist below the raceway surface, see equation (1).

$$
\ln \left(\frac{1}{S_{i}}\right)=A N^{e}\left(\int_{V_{r}} H\left(\sigma_{\mathrm{i}}-\sigma_{\mathrm{u}}\right) \frac{\left(\sigma_{\mathrm{i}}-\sigma_{\mathrm{u}}\right)}{z_{\mathrm{i}}^{\prime h}} d V\right)
$$

These stresses are evaluated by the failure criterion by DANG VAN [20] with which the hydrostatic stress state, hoop and residual stresses can be considered.

\section{Results and discussion}

After the second step the residual stresses follow as presented in Figure 6. The peak von Mises stresses concentrate in three big areas around the indentation. Two of them are directly at the surface to the left and the right of the indentation. The third area is located approximately $100 \mu \mathrm{m}$ below the indentation. The areas are slightly shifted to the direction rolling direction. In the case of the analysis with residual stresses (left), the stresses drop almost to zero at $300 \mu \mathrm{m}$ and rise again at the bottom at $400 \mu \mathrm{m}$. The peak value is $1885 \mathrm{~N} / \mathrm{mm}^{2}$. In the case without residual stresses (right), the stresses do not fade as much and stay constant from $100 \mu \mathrm{m}$ to $400 \mu \mathrm{m}$ of depth. The peak value is $1846 \mathrm{~N} / \mathrm{mm}^{2}$. Below that the hydrostatic stresses are presented. Here the overall stress level in the case with residual stresses is increased. The peak for the residual stress case is $3896 \mathrm{~N} / \mathrm{mm}^{2}$ whereas in the case without residual stresses the peak is $3685 \mathrm{~N} / \mathrm{mm}^{2}$.

These stresses are evaluated with the equations shown above and the resulting bearing fatigue life is calculated, see Figure 7 . The $\mathrm{L}_{10}$ fatigue life of the analysis with residual stresses is $1.97 \cdot 10^{7}$ revolutions whereas the case without residual stresses reaches a $\mathrm{L}_{10}$ of $2.06 \cdot 10^{7}$ revolutions. This means even a decrease in fatigue life of around $4.6 \%$, which is not significant. This indicates that there is no benefit from the residual stresses induced by manufacturing with the parameters chosen in [11] which were optimized for the classical subsurface fatigue mechanism and not for surface initiated fatigue triggered by indentations. The fatigue life from [11] is illustrated for comparison. The $\mathrm{L}_{10}$ here is $3.61 \cdot 10^{8}$ revolutions. 
The decrease is due to the complexity of the stress field that arises from superposition of the different stresses. Due to the particle indentation a residual stress state that varies vastly between high tensile and compressive hydrostatic stresses. The residual stresses induced during the manufacturing decrease the compressive stresses while the tensile stresses are enhanced.

\section{Conclusion and future works}

A two-step FE model was developed that accounts for plastic-elastic behavior and isotropic hardening of bearing steels. In the first step residual stresses emerging from particle indentation and the remaining indentation depth and diameter were calculated. In the second step these residual stresses were applied to the bearing model as initial conditions as well as the Hertzian contact pressure. The distribution of the pressure was altered using an analytical approach using the indentation diameter and depth of the indentation. Step two, then, was conducted with and without artificially induced residual stresses and the resulting stresses were evaluated with the fatigue life concept of IOANNIDES and HARRIS.

The study has shown that artificially induced residual stresses with the amount and depth as presented in [11] can decrease the fatigue life of roller element bearings in the case of particle indentations on the bearing raceway. However, residual stresses that are specifically customized for these stresses in the case of particle indentation by an appropriate choice of amplitude and depth of the stresses might have a positive effect. A combination of different sphere sizes during the deep rolling procedure could induce residual stresses in a wider range and closer to the surface.
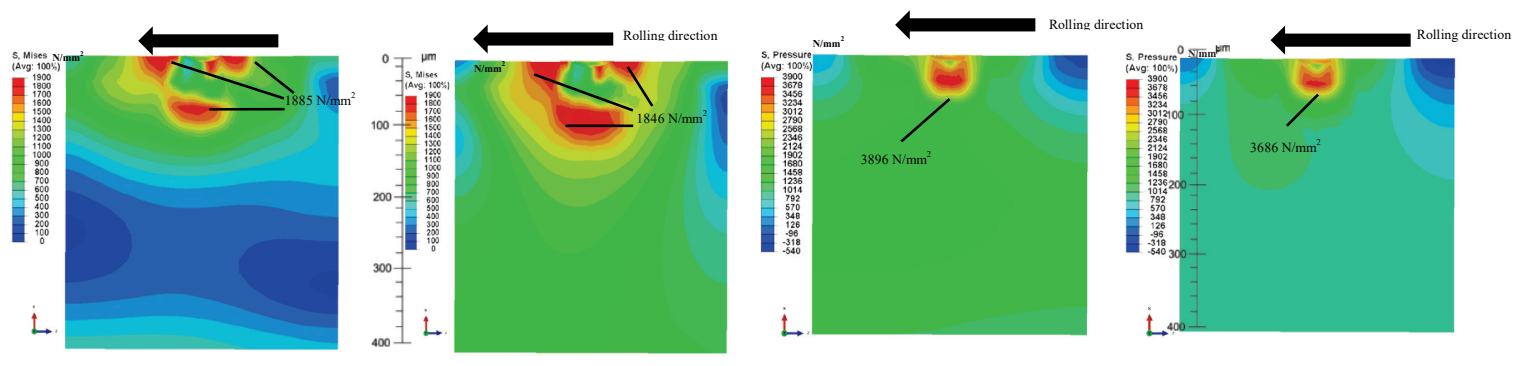

Fig. 6: Stresses of the second step. Analysis with residual stresses (left) and without residual stresses (right). Comparison of von Mises stresses (top) and hydrostatic stresses (bottom).

In [21] HAMER et. al. found similar results as presented in this study in which they investigated different geometries of indentations such as grooves. In [22] Ko and IOANNIDES found opposite results to those presented in this study. They used larger indentations and did not consider the hardening behavior of the material. In return they examined a bigger variety of parameters.

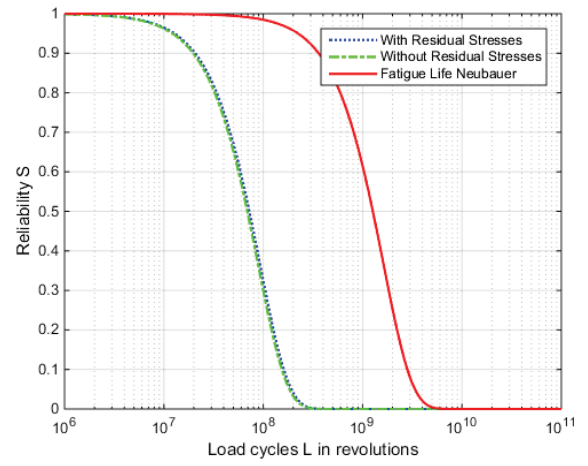

Fig. 7: Comparison of the evaluation of the fatigue life calculation.

Since the model focused on the most heavily loaded volume of the bearing and ignored the major part of the bearing volume it can only provide a tendency. To validate the results, experiments will be performed both on bearings with and without residual stresses that have indented surfaces and on reference bearings for comparison. Furthermore the FE model will be enhanced to allow for the 
calculation of the entire loaded volume of the bearing. Different distributions of manufacturing induced residual stresses will be studied.

\section{Acknowledgement}

Thanks go to Mr. NeUBAUER on whose works this study is based and whose data and FE Models were provided by the author. This work was sponsored in part by the DFG (German Research Center) within the SPP1551 in the context of the research program "Resource efficient Machine Elements".

\section{References}

[1] LundBerg, G.; PAlmgren, A.: Dynamic Capacity of Rolling Bearings. In: Generalstabens Litografiska Anstalts Förlag, 1947.

[2] WeIBULL, W.: Strength of Materials. In: Generalstabens Litografiska Anstalts Förlag, 1939.

[3] VOSKAMP, A.: Microtructural changes during rolling, 1996.

[4] ZARETSKY, Erwin V.; BRANZAI, Emanuel V.: Rolling-Bearing Service Life Based on Probable Cause for Removal - A Tutorial. In: Tribology Transactions, 2016.

[5] SIRCAR, S. D.: Rolling Contact Fatigue of Hypoeutectoid Steel. Karlsruhe, Karlsruher Institut für Technologie. Dissertation. 2015

[6] Gabelli, A., IoAnnides, E., Miglietta, E.: Increased Life Performance of Rolling Element Bearings in Gearboxes and Transmissions. In: VDI-Berichte 1230, 1996, pp. 631-645.

[7] Bergling, G. ; Gabelli, A. ; IOANnides, E.: An analytical formulation for the life of rolling bearings, Bd. 137. In: Acta polytechnica Scandinavia: Mechanical engineering series.

[8] IOANNIDES, E. ; HARRIS, Tedric A.: A new Fatigue Life Model for Rolling Bearings. In: Journal of Tribology 107, 1985, No. 1, pp. 367-378

[9] ISO 281:2007. 2007-02-15. Rolling bearings - Dynamic load ratings and rating life

[10] ISO/TS 16281:2008. 2008-06-15. Rolling bearings - Methods for calculating the modified reference rating life for universally loaded bearings

[11] NeUBAUER, T.: Betriebs- und Lebensdauerverhalten hartgedrehter und festgewalzter Zylinderrollenlager. Leibniz Universität Hannover, IMKT. Dissertation. 2015

[12] HACKE, B.: Wälzlagerlebensdauer-Windgetriebe : FVA 541. In: FVA-Forschungsheft, 2011, No. 967

[13] Kral, E. R. ; Komvopoulos ; Bogy, D. B.: Elastic-Plastic Finite Element Analysis of Repeated Indentation of a Half-Space by a Rigid Sphere. In: Journal of applied mechanics 60, 1993, pp. 829-841

[14] AnTAlucA, Eduard ; NÉlias, Daniel: Contact Fatigue Analysis of a Dented Surface in a Dry ElasticPlastic Circular Point Contact. In: Tribology Letters 29, 2008, No. 2, pp. 139-153

[15] Xu, Gang ; SAdeghI, Farshid ; HoEPrich, Michael: Residual Stresses Due to Debris Effects in EHL Contacts. In: Tribology Transactions 40, 1997, No. 4, pp. 613-620

[16] WarhadPande, Anurag ; Sadeghi, Farshid ; Evans, Ryan D. ; KotZalas, Michael N.: Influence of Plasticity-Induced Residual Stresses on Rolling Contact Fatigue. In: Tribology Transactions 55, 2012, No. 4, pp. $422-437$

[17] Ko, C. N. (Hrsg.); IOANNIDES, E. (Hrsg.): Debris denting — the associated residual stresses and their effect on the fatigue life of rolling bearing: an FEM analysis. The University of Leeds : Elsevier, 1989 (Tribology Series Proceedings of the 15th Leeds-Lyon Symposium on Tribology held at Bodington Hall)

[18] BIBOULET, N.: Influence of indentations on rolling bearing life. Lyon, Institut National des Sciences Appliquées. Dissertation. 2008

[19] Coulon, S. ; Ville, F. ; Lubrecht, A. A.: Effect of a Dent on the Pressure Distribution in Dry Point Contacts. In: Journal of Tribology 124, 2002, No. 1, pp. 220-223 - Überprüfungsdatum 2016-06-07

[20] Dang VAn, K. (Hrsg.): Multiaxial Fatigue Limit - A New Approach. New Dehli, 1984 (Int. Conf. Fract. Mech., ICF 6)

[21] Hamer, J. C. ; Lubrecht, A. A. ; LOANnideS, E. ; SAYles, R. S.: Surface damage on rolling elements and its subsequent effects on performance and life, Bd. 14. In: Proceedings of the 15th Leeds-Lyon Symposium on Tribology held at Bodington Hall, The University of Leeds, pp. 189-197

[22] Ko, C. N. ; LOANNIDES, E.: Debris denting-The associated residual stresses and their effect on the fatigue life of rolling bearing: An FEM analysis, Bd. 14. In: Proceedings of the 15th Leeds-Lyon, Tribology Series, pp. 199-207 